\title{
ISIS Y SARAPIS: DIFUSIÓN DE SU CULTO EN EL MUNDO GRECORROMANO
}

This paper deals with the diffusion that the couple formed by Isis and Sarapis reached in the Greek and Roman world, with the nature of their cult and the causes of its diffusion. The authress tries to proof that the incubatio was practised in their temples and that the therapeutical powers attributed to these two deities were a decisive factor fot their spread and universalization.

1. Antecedentes del culto: Heródoto, conocedor excepcional del mundo griego y también egipcio, escribe: «No todos los egipcios adoran igualmente a los mismos dioses, salvo a Isis y Osiris que dicen es Dioniso» ${ }^{1}$, «Isis es Deméter en la lengua de los griegos» ${ }^{2} \mathrm{y}$ «Osiris es Dioniso en lengua griega» ${ }^{3}$. Revelan estas palabras que las divinidades egipcias más universales fueron Isis y Osiris. Revelan además la capacidad de sinnetismo del hombre griego al equiparar a Isis con Deméter y a Osiris, al que sustituirá Sarapis, con Dioniso. Las palabras de Heródoto son también el mejor anuncio de la difusión que habría de tener el culto de los dioses egipcios en el mundo helenístico y posteriormente en el romano.

La leyenda de Isis, atestiguada ya en los textos de las pirámides de Sákkara de la quinta y sexta dinastía de faraones (tercer milenio a.C.),

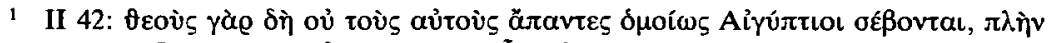

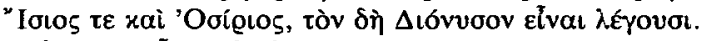

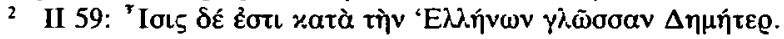

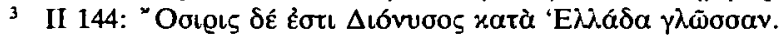


la recoge Plutarco en su tratado Sobre Isis y Osiris (Mor. 315D-384B), que dedica a su amiga Clea, sacerdotista de la diosa. La historia de Isis está íntimamente unida, tanto en los textos de las pirámides como en Plutarco, a su esposo y hermano Osiris, primitivo dios agrario, que encarnaba el suelo húmedo y fértil en oposición a la sequedad del desierto, personificada en su hermano Seth o Tifón. F.Le Corsu ${ }^{4}$ ha señalado que «el conflicto entre Osiris y Seth es el conflicto entre tierras fértiles y tierras áridas, tal como la configuración tan peculiar de Egipto se lo mostraba cada día a sus habitantes». Sin duda, esta oposición reflejaba también un conflicto entre el Alto y Bajo Egipto. Según Plutarco, Isis y Osiris se enamoraron y se unieron, antes de nacer, en las tinieblas del seno materno. Mediante un engaño Tifón mató a su hermano Osiris y lo tiró al río metido en un cofre que la corriente llevó hasta el país de Biblos. Isis en su dolorida búsqueda al fin lo encontró, lo sacó del cofre y le rindió honras fúnebres, pero Tifón halló de nuevo el cuerpo de su hermano a pesar de que Isis lo había escondido, lo despedazó en catorce partes (en veintiséis según Diodoro de Sicilia, I 21) y los dispersó. Isis buscó los trozos dispersos del cuerpo de Osiris y los encontró todos menos el falo. Pudo así reconstruir el cuerpo de su esposo al que embalsamó y devolvió la vida por toda la eternidad.

Reconocemos en este mito los elementos fundamentales de las religiones agrarias, típicas del Mediterráneo oriental ${ }^{5}$ : muerte del dios de la fertilidad por un hermano que personifica la sequía, período de dolor y desolación en el mundo de los vivos y la resurreción del dios. En palabras de Le Corsu «el asesinato del ser bueno por el malvado, la búsqueda de Isis y la resurrección del esposo gracias a sus poderes de maga curadora serán los elementos básicos de la iniciación de los misterios de Isis, cuando la diosa haya conquistado el mundo mediterráneo». Esta conquista sucederá en época helenística. En esta época Isis aparece no sólo. como la hermana y esposa de Osiris y madre

4 Isis. Mythe et mystères, París 1977, p. 7.

5 Ibid, p. 13 y cf. F. Solmsen, Isis among the Greeks and Romans, Londres 1979, en p. 65 afirma que el mito de Isis y Osiris apunta a un esquema dual, en que dos principios, el del bien y el del mal, se oponen en perenne lucha por la búsqueda del dominio. 
ideal, como aparecía ya en la mitología egipcia, sino también es una divinidad cósmica, que domina sobre cielo, mar, tierra y tinieblas; es la encarnación de la tierra fértil del Delta, promotora de la agricultura, maga y curadora, además de protectora del derecho y de las costumbres. Así lo revela el texto de una aretalogía de Isis aparecida en Maronea $^{6}$, que data del s. II a. C. y que fue escrita en acción de gracias por una curación. Isis en esta época era ya una diosa universal,

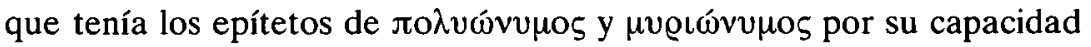
de adaptación a todas las circunstancias, y que además prestaba atención individualizada a sus devotos concediéndoles salud y bienestar. Consideramos que esa función terapéutica de Isis y Sarapis fue uno de los elementos decisivos, por lo que tiene de trato personal del dios y sus fieles, en la difusión del culto de las divinidades egipcias en el mundo grecorromano.

A diferencia de Isis, diosa de tradición multisecular en el pensamiento religioso, Sarapis hace sus aparición en el culto en suplantación de Osiris en época helenística. «Tú has tomado a Sarapis por esposo», le dice a Isis el autor del encomio de Maronea ${ }^{7}$, dando un claro protagonismo a la diosa frente a su divino compañero, si bien parangona a la pareja divina con Helios y Selene. La etimología de Sarapis procede de la fusión del nombre de Osiris y el de Apis ${ }^{8}$. Así los egipcios en principio rindieron culto a Oserapis, nombre que los griegos helenizaron en la forma de $\Sigma$ ágajıৎ. Sarapis es un dios que carece de mito. Según A. Alvarez de Miranda ${ }^{9}$ es «uno de los más curiosos pseudomorfemas de la historia de las religiones, por cuanto que su figura

6 Y. Grandjean, Une nouvelle arétologie d'Isis à Maroneé, Leiden 1975.

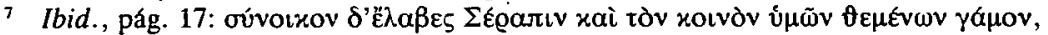
тоі̄ ن்

8 Cf. U. Wilcken, Urkunden der Ptolomäerzeit I, Berlín y Leipzig 1922-1927, pp. 77-89. Esta etimología está atestiguada por primera vez en Atenodoro de Tarso, autor del S. I. a. C., quien es citado por Clemente de Alejandría en su Protréptico (IV 48),

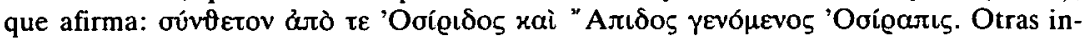
terpretaciones sobre la etimología de Sarapis pueden leerse en J. E. Stambaugh, Sarapis under the Early Ptolomies, Leiden 1972, pp. 36 ss.

9 Las religiones mistéricas, Madrid 1961, p. 154. Son interesante e innovadores los dos artículos de P. M. Fraser sobre el culto de Sarapis: «Two Studies on the Cult of Sarapis in the Hellenistic World», Opuscula Atheniensia III 1960, pp. 1-54 y "Current Problems concerning the early History of the Cult of Sarapis», Opuscula Atheniensia V, 1965, pp. 23-45. 
originariamente amítica sufrió un proceso de mitificación que hubo de realizarse a base de convertir la historia de sus milagros en una especie de sucedáneo del mito inexistente... y sólo como consecuencia de un prolijo proceso sincretístico se difundió por todo el mundo antiguo la figura de Sarapis al lado de la Isis y en sustitución de la Osiris».

Cuándo se dio la sustitución de Osiris por Sarapis es una cuestión debatida y que permanece aún abierta ${ }^{10}$. Hay dos tradiciones al respecto. Una atribuye los orígenes del culto al primer Ptolomeo y la otra remonta a Alejandro. Hasta hace poco era generalmente admitido que Ptolomeo I Soter (305-283 a. C.) introdujo en Alejandría esta divinidad con el fin de unificar la religión de griegos y egipcios. Se basaba esta creencia en las palabras de Plutarco (Mor. 361F-362B), quien afirma que el monarca helenístico recibió en sueños la orden de trasladar una estatua colosal. Un viajero de nombre Sosibio dijo haber visto en Sinope una estatua como la que describía el monarca. El rey envió a dos emisarios para que la transportaran desde Sinope a Alejandría. «Cuando, una vez trasladada, fue expuesta a la vista -relata el queronense- Timóteo, el intérprete de leyes sagradas, y Manetón, el sebenita, junto con sus respectivos asociados, conjeturando que era una estatua de Plutón... persuaden a Ptolomeo de que no era la estatua de ningún otro de los dioses sino la de Sarapis. Allí de donde llegó no se llamaba así, pero una vez trasladada a Alejandría adquirió el nombre de Sarapis, apelación de Plutón entre los egipcios» ${ }^{11}$. Junto a esta tradición ptolomaica de los orígenes del culto de Sarapis en Alejandría, ya desde la antigüedad hay otra que retrotrae los orígenes de este culto a Alejandro Magno. Tácito en su Historia (IV 84) dice que en Racotis, localidad sobre la que Alejandro fundó la ciudad que lleva su nombre, fuerat illic sacellum Sarapidi atque Isidi antiquitus sacratum. También el Pseudo Calístenes (I 33) relata que

10 Cf. H. Idris Bell, Cults and Creeds in Graeco-Roman Egypt, Liverpool 1957, pp. 19 ss; S. K. Heyob, The Cult of Isis among Women in the Graeco-Roman World, Leiden 1975, pp. 5 ss.; L. Vidman, Isis und Sarapis bei den Griechen und Römern, Berlín 1970, pp. 19 ss. (a partir de aquí se citará Isis) y J. E. Stambaugh, o. c. pp. 6 ss.

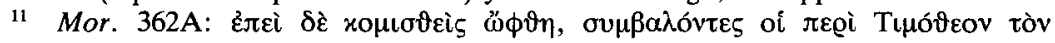

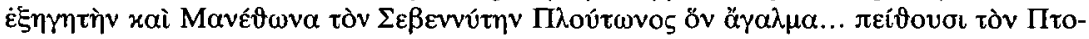

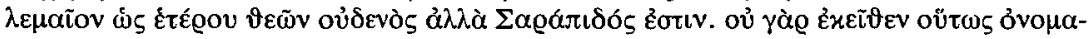

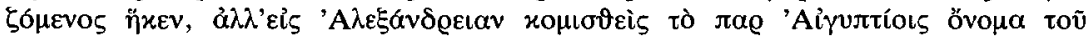

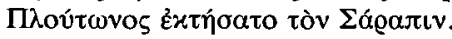


la fundación del Serapeo de Alejandría fue obra de Alejandro. Añádase que una inscripción de Hircania, fechada entre los años 281-261, alude a un templo de Sarapis en esta localidad, que ya fuera fundación de Alejandro, como sugiere C. B. Welles ${ }^{12}$, o de algún grupo de soldados egipcios, como apunta P. Fraser ${ }^{13}$, lo que es evidente, afirma L.Vidman ${ }^{14}$, es que no fue fundación ptolomaica. Tal vez tenga razón J.E.Stambaugh ${ }^{15}$ al distinguir en los orígenes del culto de Sarapis en Alejandría, la introducción del culto propiamente dicha, que probablemente se deba a Alejandro, quien muy bien pudo convertir un dios egipcio en una divinidad, a la que tanto la población griega como la indígena pudiera adorar, y la introducción de la estatua del dios como elemento importante del culto, lo que es posible que fuera idea de Ptolomeo I, según relata Plutarco.

2. Templos: Los templos desde donde se difundió este culto están en el Norte de Egipto, en concreto, en Menfis y Alejandría. El Serapeo de Menfis es, según Pausanias (I 18,4), el más antiguo de Egipto. Las descripciones de Estrabón (XVII 1,32), Heródoto (III 28) y Ammiano Marcelino (XXII 14,7) invitan a imaginar la magnificencia del complejo. Se hallaba próximo a la colina Sinopion, cuyo nombre pudo originar la leyenda del traslado de la imagen de Sarapis desde Sinope a Alejandría, según argumentan quienes defienden que el culto procede de Menfis ${ }^{16}$. Estrabón relata que el Serapeo griego se hallaba en la ladera oriental de la zona fértil de la colina y que de allí partía hacia el oeste una larga avenida, jalonada por unas trescientas setenta $o$ trescientas ochenta esfinges. Algunas de ellas se han hallado en las excavaciones que llevó a cabo el arqueólogo francés Mariette entre los años 1851-1854. En el año 1820 se encontró cerca del Serapeo de Menfis una vasija con papiros que contienen noticias sobre la vida del templo: cartas, cuentos, prescripciones rituales e incluso referencias oníricas, probablemente de los enfermos que acudían al templo con la

12 «The discovery of Sarapis and the foundation of Alexandria», Historia 11, 1962, pp. 271-298.

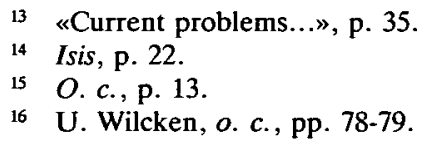


esperanza de curarse. Consideramos muy plausible que este templo sirviera de modelo al que se construyó en la nueva ciudad de Alejandría.

Si el de Menfis fue el más antiguo, el Serapeo de Alejandría, relata Pausanias (I 18,4), fue el templo más magnificente de cuantos se construyeron en Egipto. Estaba formado por una serie de dependencias y santuarios en donde además de a Sarapis se rendía culto a Isis, a Anubis, a Astarté e incluso a Asclepio. Las sucesivas excavaciones realizadas desde el año 1896 han permitido conocer su situación y el hallazgo de inscripciones bilingües grabadas en placas de oro constata el esplendor del que hablaba Pausanias. Avieno (Or. 357) y Ammiano Marcelino (XXII 16) describen el suntuoso complejo y Rufino en su Historia Eclesiástica (II 23) relata su destrucción. Según Tácito (IV 84) se construyó en una colina donde ya había primitivamente un templo al suroeste de la ciudad. Cien escalones conducían a unas explanadas abiertas, en cuyo centro se hallaba el templo propiamente dicho, construido con piedras preciosas y rodeado de columnas de mármol. En la fachada del templo había una ventana a través de la que los rayos del sol naciente tocaban los labios de la estatua de Sarapis el día en el que se conmemoraba su fundación. La tradición atribuía esta estatua al escultor Briaxis ${ }^{17}$. Una sala de columnas, dos obeliscos, habitaciones para el culto y una biblioteca completaban el complejo. El templo fue derruido en el año 391 por el obispo Teófilo y parte de él se convirtió después en una iglesia. «A pesar de tan drásticas medidas -afirma N. Fernández Marcos ${ }^{18}$ - Isis seguía seduciendo a la población de Alejandría y alrededores, que acudía al lugar del santuario transformado en iglesia a implorar su protección, consultar su oráculo y sobre todo a obtener un sueño terapéutico por el procedimiento de la incubatio». Otros santuarios de Egipto que merecen tenerse en cuenta por la actividad salutífera que en ellos desarrollaron Isis y Sarapis son los de Menuti y Cánope, dos localidades muy próximas a la ciudad de Alejandría.

17 Clemente de Alejandría en su Protréptico (IV 48) afirma que según Atenodoro no se trataba de Briaxis, el ateniense, sino de un homónimo suyo. Sobre la discusión de esta problemática, cf. J. E. Stambaugh, o. c., p. 15-26 y W. Hornbostel, Sarapis, Leiden 1973, pp. 3 ss.

${ }_{18}$ Los Thaumata de Sofronio. Contribución al estudio de la incubatio cristiana, Madrid 1975, pp. 14-15. 
Como observa acertadamente J.E.Stambaugh ${ }^{19}$, el Sarapis de Menfis adquirió de Osiris sus rasgos de dios del mundo de ultratumba, lo que permitió su identificación con Dioniso, como ya atestigua Heródoto (II 42,2 y 144,3). El Sarapis de Alejandría, en cambio, desde sus orígenes más helenizado y, por tanto, más antropomorfo, fue el dios de aquella ciudad mezclada y cosmopolita, rey y señor de sus habitantes. Su propia representación escultórica lo acercó más a la población y le permitió adquirir los atributos de uno de los dioses más populares de entonces como era Asclepio $^{20}$, hasta el punto de llegar a una cierta identificación como lo atestigua una inscripción de Lebena (Creta) en

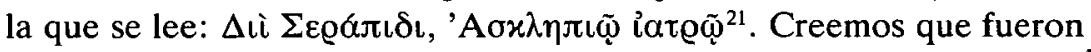
los rasgos más humanos de Isis y Sarapis y sobre todo sus virtualidades terapéuticas lo que más les acercó a sus devotos, al conectar mejor con la sensibilidad religiosa de la época, que demandaba respuesta personal a necesidades individualidades, cansada ya de los distantes y fríos dioses de las poleis.

3. Naturaleza del culto: El culto isíaco gira en torno a la alegría de la diosa al encontrar el cadáver de su esposo y darle de nuevo vida.

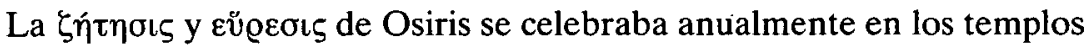
de Isis en los últimos días de octubre y primeros de noviembre. Este hecho, ha escrito $\mathrm{O}$. Gigon ${ }^{22}$, que hablaba a los fieles de muerte $y$ resurrección, les confería seguridad en su propio destino futuro. Esa esperanza en una nueva vida se refleja en los ritos mistéricos que se celebraban en los templos de los dioses egipcios. Apuleyo de Madaura (125-180) en el libro XI de su Metamorfosis ${ }^{23}$ ofrece un excelente testi-

19 O. c., pp. 55 y 90 .

2o lbid., pp. 76-78.

21 Cf. L. Vidman, Sylloge inscriptionum religionis Isiacae et Sarapiacae, Berlín 1969 (a partir de aquí se citará SIRIS), n. 161.

${ }_{22}$ La cultura antigua y el Cristianismo (trad. esp. de M. Carrión), Madrid 1970, p. 136.

${ }^{23}$ Cf. M. C. Marín Ceballos, «La religión de Isis en Las Metamorfosis de Apuleyo", Habis IV, 1973, pp. 127-179, esp. pp. 150 ss.; R. E. Witt, Isis in the Graeco-Roman World, Londres 1971, pp. 152 ss. y W. Wittmann, Das Isisbuch von Apuleius, Stuttgart 1938. Las Metamorfosis de Apuleyo fueron traducidas al castellano en 1513 por Diego López de Cortegana, traducción que ha sido de nuevo publicada con una amplia introducción por C. García Gual en 1988 en Madrid. Las Metamorfosis también han sido traducidas al castellano por L. Rubio, Madrid 1978. 
monio literario de cómo debían de ser las ceremonias de iniciación en el templo de Isis. El neófito, cuando recibía la señal de la diosa, debía someterse a una rigurosa preparación mediante lecturas, ayunos y purificaciones durante una larga estancia en el templo (XI 23). Las actividades cultuales debían de ejercer una poderosa tensión psicológica en el iniciando que esperaba con emoción e impaciencia la señal de la diosa para celebrar su entrada en la nueva religión a manera de muerte voluntaria y salud obtenida por la gracia (XI 21). Cuando a Lucio, el protagonista de la obra de Apuleyo, Isis le anunció mediante un sueño que había llegado el día anhelado, tras una lectura oculta a la curiosidad de los profanos (a curiositate profanorum lectione munita, XI 22), el sacerdote le puso ante los pies de la diosa, le dio ciertos mandamientos que debía guardar en secreto y en presencia de todos le dijo que debía ayunar durante diez días, pasados los cuales y cumplidos los preceptos rituales, lo vistió con una túnica de lino blanco, lo tomó de la mano y lo llevó a la parte más íntima del santuario (XI 23).

Sobre las ceremonias de la iniciación evidentemente no nos ilustra, pero dice unas palabras que son claves para comprender el carácter mistérico de esta práctica religiosa y el sincretismo que se dio entre los misterios egipcios de Isis y los misterios griegos de Eleusis. Cito textualmente las palabras de nuestro personaje: «Quizás, tú, lector estudioso, podrás aquí con ansiedad preguntar qué es lo que se dijo y se hizo después; te lo diría si fuese lícito decirlo, lo conocerías si fuese lícito que lo oyeras. Pero en igual culpa incurrirían los oídos y la lengua, <ésta por su impía locuacidad> y aquéllos por su curiosidad temeraria. Pero no te atormentaré prolongado tu angustia, a tí que tal vez estás impaciente por una inquietud religiosa. Así, pues, escucha, mas cree que son cosas verdaderas: llegué a la frontera de la muerte, pisé el umbral de Prosérpina, anduve por todos los elementos y he retornado. En medio de la noche vi brillar el sol con resplandeciente luz. Tuve acceso a la presencia de los dioses inferiores y superiores y los adoré muy de cerca» ${ }^{24}$. El iniciando llega, pues, a la muerte de su

24 Apuleyo, Metamorfosis VI 23: Quaeras forsitan satis anxie, studiose lector, quid deinde dictum, quid factum; dicerem, si dicere liceret, cognosceres, si liceret audire. Sed 
vida anterior y parece que accede tanto al mundo de los muertos como a los secretos del universo e incluso al mundo de los dioses. Este día es el comienzo de una nueva vida. Según O. Gigón ${ }^{25}$, esa epoptía le da la seguridad de que también en el futuro podrá substraerse al común destino de los mortales y experimetar la intimidad con los dioses. Esta solemnidad era celebrada con tres días de fiesta en que se continuaban los banquetes y las reuniones ${ }^{26}$.

Los testimonios de la arquitectura, ha señalado $F$. Dunand ${ }^{27}$, son también significativos en lo que respeta al conocimiento de la naturaleza de los misterios. Algunas de las cámaras subterráneas del Iseo de Pompeya parecen, en efecto, destinadas a las pruebas de iniciación. Dunand distingue en ellas un purgatorium o lugar de purificación, un mégaron o sala de pruebas y un ecclesiasterion o sala de misterios en donde se celebrarían los banquetes rituales de los isíacos. Rufino (Hist.Ecl. XI 23) en su descripción de Serapeo de Menfis también habla de ciertas construcciones subterráneas ocultas que servían para "funciones diversas y ceremonias secretas» (diversis ministeriis el clandestinis officiis).

4. Difusión del culto en Grecia: Macrobio (Sat. I 20, 16-17) relata que el rey de Chipre Nicocreonte se dirigió a Sarapis hacia el año 312 a. C. para interrogarle sobre qué tipo de divinidad era. Sea o no cierto el testimonio de Macrobio, se ha hallado en la ciudad chipriota de Solos una inscripción datada por P.M. Fraser ${ }^{28}$ en el s. III a. C., que

parem noxam contraherent et aures et lingua, <ista impiae loquacitatis >, illae temerariae curiositatis. Nec te tamen desiderio forsitan religioso suspensum angore diutino cruciabo. Igitur audi, sed crede quae uera sunt . Accessi confinium mortis et calcato Proserpinae limine per omnia uectus elementa remeaui, nocte media uidi solem candido coruscantem lumine, deos inferos et deos superos accessi coram et adoraui de proxumo.

25 O. c. p. 138.

26 Sobre el estado anímico de los que se iniciaban en los misterios, cf. Aristóteles (frag. 45, Rose); Dión de Prusa XII 33; Estobeo V 1089 Hense y Proclo, Comentarios a la teología de Platón I 3, p. 7.

27 «Les mystères égyptiennes aux époques hellénistique et romaine» en F. Dunand (ed), Mystères et syncretismes, París 1975, p. 37.

28 «Two Studies...», p. 46. 
menciona un templo erigido por orden de Sarapis ${ }^{29}$. Dedúcese de estos datos que en Chipre el culto a Sarapis era conocido desde el s. III a. C. o antes ${ }^{30}$.

Pero la inscripción más antigua del culto de Isis y Sarapis de fuera de Egipto procede, según Fraser ${ }^{31}$, de la ciudad caria de Halicarnaso ${ }^{32}$. Fraser la fecha en el s. IV a. C., aunque Hirschfeld ${ }^{33}$ da razones para datarla a mediados del III. Ahora bien, dátese en el s. IV o a mediados del III, lo cierto es que se trata de una inscripción de unos particulares que llevan nombre griego. Otra inscripción del s. III encontrada en Halicarnaso ${ }^{34}$ atestigua que en aquella época había un templo consagrado a las dos divinidades egipcias en esa ciudad ${ }^{35}$.

En el Iseo de Eretria de la isla de Eubea ha aparecido una inscripción $^{36}$, que P. Roussel y P. Fraser fechan a finales del s. IV y N. Papadakis, su primer editor, fechaba en el s. III, cuyo texto, que dice:

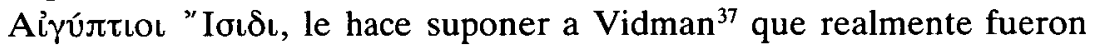
egipcios los primeros adoradores de Isis en Grecia. Los restos arqueológicos del Iseo de Eretria proceden del s. III. Se han encontrado restos de lamparillas con manchas de humo, que debieron de usarse en las procesiones nocturnas de la diosa. Hay también atestiguada desde el s. III una asociación consagrada al culto de los dioses. Vidman considera que el templo de Eretria seguía el modelo del Serapeo de Menfis y no el tipo de templo griego. Todo hace pensar que fueron comerciantes egipcios quienes introdujeron el culto de Isis en Eretria.

Uno de los centros culturales más importantes y mejor documentados del culto de Isis y Sarapis fue la isla de Delos. P. Roussel ${ }^{38}$ ha

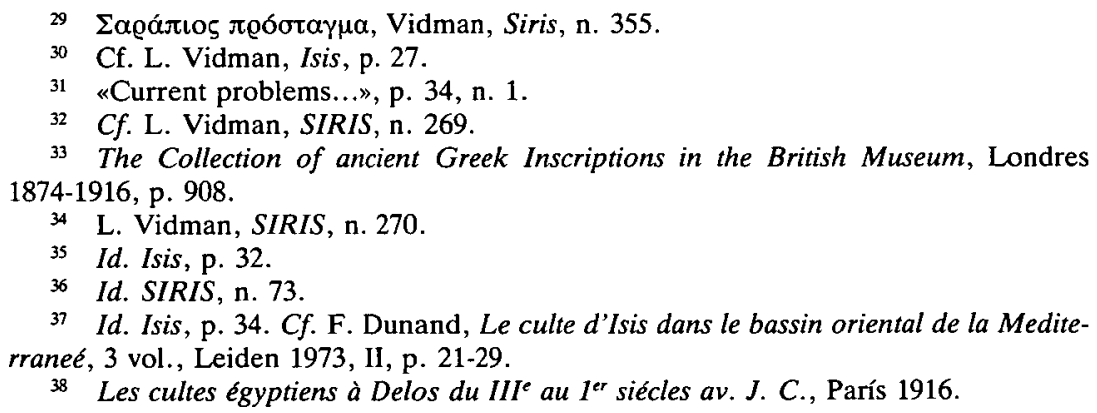

38 Les cultes égyptiens à Delos du III au ler siécles av. J. C., París 1916. 
publicado más de trescientas inscripciones halladas en este complejo compuesto por tres Serapeos y un Iseo. El más célebre fue el designado por los arqueólogos como Serapeum $C$. En él se rindió culto oficial a las divinidades egipcias. Según F. Dunand ${ }^{39}$ en el año 215 a. C. podría haber estado ya construido, aunque L. Vidman ${ }^{40}$ lo sitúa en fecha algo posterior. De cualquier modo no hay datos que avalen con seguridad la fecha exacta de estas construcciones. El Serapeum $C$ tenía una entrada monumental, flanqueada por propileos, continuaba una gran avenida de unos noventa metros y al final se abría una amplia explanada donde se encontraba el templo. Una gran escalinata permitía acceder a las tres capillas dedicadas a Isis, Sarapis y Anubis. El más antiguo era el Serapeum A. Una larga inscripción relata cómo el culto de Isis y Sarapis fue implantado en esta isla a principios del s. III por un sacerdote egipcio procedente de Menfis, llamado Apolonio y que su hijo Demetrio y Apolonio II, nieto del primer Apolonio, continuaron la tradición (IG XI 4,1299). Según Vidman ${ }^{41}$, Apolonio I debió de llegar de Menfis a Delos con la estatua del dios aproximadamente entre los años 287 y 250 a. C. Su hijo Demetrio debió de mantener viva la tradición del culto a Sarapis y Apolonio, hijo de Demetrio, debió de ser consagrado sacerdote de Sarapis antes del 205 a. C. Apolonio II, el nieto, relata cómo recibió en sueños la orden de la divinidad de construir un templo. El dios le señaló incluso el lugar en

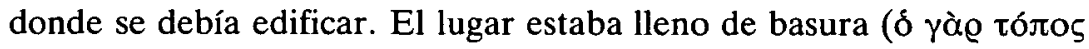

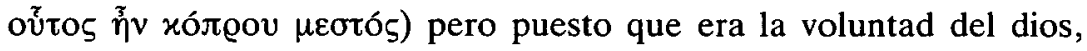
nos informa la inscripción, se realizó la compra del lugar y en seis meses le fue preparado el templo. En el año 88 a. C. este monumental complejo desapareció con el saqueo de Mitrídates.

En otras islas del Egeo como Rodas, Quíos, Tera y Samos se han encontrado inscripciones que atestiguan que, al menos desde el s. III a. C., se rendía culto en estas islas a Isis y a Sarapis. En la isla de Rodas el culto a Isis y Sarapis está atestiguado epigráficamente desde

39 Le culte d'Isis..., II p. 89.

40 Isis, p. 36.

41 Ibid. p. 35. 
mediados del s. III a. C. en Rodas, Lindos y Camiro, sus tres ciudades principales. Rodas siempre tuvo excelentes relaciones políticas y comerciales con Egipto, lo que favoreció la recepción de las divinidades egipcias en la isla y su culto oficial junto con las divinidades autóctonas. En Lesbos, isla que estuvo bajo el dominio de los Ptolomeos, también encontramos inscripciones a Isis y Sarapis que deben fecharse en el s. III a. C. ${ }^{42}$.

En las principales ciudades de Asia Menor -Efeso, Esmirna, Cos, Dídima, Priene, Iaso, Bargilia, Milasa, Heraclea, Mileto- los testimonios epigráficos pueden datarse a partir de finales del s. III a. C. o principios del II. En Jonia los vestigios más antiguos de un templo dedicado a Isis y Sarapis se encuentran en Priene. Se ha hallado también una inscripción del s. III a. C. que contiene una serie de ritos, prescripciones y leyes, referentes al santuario egipcio. De la difusión de este culto en Priene dan cuenta numerosas estatuillas femeninas con el atuendo isíaco, halladas en las excavaciones de casas particulares ${ }^{43}$.

Vidman ${ }^{44}$ hace notar que en las inscripciones fechadas a finales del s. IV o en el s. III no se nombra como portador del culto a ningún alejandrino. En efecto, el sacerdote Apolodoro llegó a Delos desde Menfis, el sacerdote Vafres llegó a Demetria en Tesalia desde Busiris y el sacerdote del Serapeum de Samos procedía de Cánope. Tampoco antes del año 166 aparece atestiguado ningún personaje de Alejandría en las inscripciones de Delos. Estos datos los arguyen Roussel, Fraser y Vidman ${ }^{45}$ en favor de que la expansión del culto de Serapis no se debió a una política imperialista de los Ptolomeos. Es cierto que la iniciativa privada debió de jugar un papel importante en la difusión del culto pero no se puede pasar por alto el hecho de que en las zonas de dominio lágida, como Tera, Lesbos, Samos, etc., el culto de Isis y Sarapis estuvo muy favorecido y desde el s. III encontró amplia aceptación.

42 L. Vidman, SIRIS, n. 258. Cf. F. Dunand, Le culte d'Isis... III, p. 19 ss y 48 ss.

43 Cf. F. Dunand, Le culte d'Isis... III, pp. 36 ss.

44 Isis, p. 46.

45 Ibid. 
Respecto a la Grecia continental, en Atenas el culto de Isis y Sarapis estuvo favorecido por la relación que en el s. III mantuvo esta ciudad con la isla de Delos. No obstante, ya en el s. IV a. C., Isis era conocida en Atenas, como lo demuestra un decreto del año 333 a. C. por el que los atenienses conceden a los de Citio un terreno para edificar un templo a Artemis, lo mismo que los egipcios tenían consagrado uno a Isis ${ }^{46}$. Pero si en el s. IV acudían a este templo sólo los comerciantes egipcios, otra inscripción del año 215, contiene un decreto de los sarapiastai ${ }^{47}$, asociación de devotos de Sarapis, tal vez de carácter privado y no reconocida oficialmente, pero que, sin duda, influía en la sociedad ateniense, pues hacia el año 200 el culto a Sarapis e Isis fue oficialmente reconocido como lo muestra una inscripción $^{48}$, que data de poco después del año 200 , en la que el sacerdote y el custodio del templo son ciudadanos atenienses. Con probabilidad el sacerdote al que se refiere esta inscripción era ya un funcionario estatal. S. Dow ${ }^{49}$, que ha realizado un exhaustivo estudio de los cultos egipcios en Atenas, explica que el culto a Sarapis e Isis tardó en reconocerse oficialmente por cuanto que los atenienses sentían cierta reticencia ante las divinidades no griegas. Pero cuando hicieron quiebra las convenciones tradicionales, esta religiosidad que había ido haciendo adeptos entre las clases más populares, los metecos y las mujeres, tomó un gran auge no sólo en Atenas sino también a partir del s. II en las otras regiones de la Grecia continental: Beocia, Fócide, el Peloponeso, la Lócride, la Argólide, Tesalia y Macedonia ${ }^{50}$.

De acuerdo con Roussel, Frasser, Vidman y Heyob el culto de Sarapis y las divinidades a él asociadas se difundió gracias a los mercaderes, a gentes que habían servido en el ejército egipcio o que habían tenido cargos oficiales en el Egipto ptolomaico o incluso a sacerdotes, comerciantes y marinos en una época en quie las relaciones comer-

46 L. Vidman, SIRIS, n. 1.

47 Ibid. n. 2.

48 Ibid. n. 3.

49 «The Egyptian Cults in Athens», Havard Theological Review XXX 4, 1937, pp. 183-232.

so Cf. Th. Brady, The Reception of the Egyptian Cults by the Greeks (330-30 b. C), Missouri 1935. 
ciales eran fluidas, y las islas de Chipre, Samos, Rodas, Delos o Eubea por su ubicación estratégica para todo tipo de relaciones políticas y comerciales tuvieron un papel fundamental en su difusión.

5. Causas de la difusión: Que las religiones mistéricas en general y el culto de Isis y Sarapis en particular se difundieran en Grecia y Roma obedece no sólo a causas políticas, económicas y comerciales sino también a la crisis espiritual e intelectual que se estaba produciendo en las conciencias de los pueblos por los que se difundía. Señala F. Cumont $^{51}$ que el éxito de estas religiones mistéricas se debe a tres factores fundamentales, el sentimental, el racional y el moral. Incidían efectivamente en los sentimientos de las personas más que la religión oficial. La religión helenística y sobre todo la religión romana estaban excesivamente subordinadas a los intereses políticos. Buscaban ante todo asegurar al estado la protección de los dioses mediante los ritos adecuados. Su liturgia, comenta con ironía Cumont ${ }^{52}$, por la minuciosidad de sus preceptos recuerda el derecho civil romano. Todo en ella estaba ritualmente codificado. Poco espacio le quedaba a la piedad espontánea del individuo. Los misterios, en cambio, actuaban sobre el sentimiento de las personas. Provocaban temor y esperanza. Movían el ánimo mediante el esplendor de sus fiestas y procesiones. Enseñaban los medios para que el alma pudiera liberarse del cuerpo, del dolor y del sufrimiento. Los dioses de las religiones mistéricas sufren, mueren y después resucitan. Sus seguidores lloran la pasión y muerte del dios y luego participan en la alegría de la resurrección. En segundo lugar, las religiones mistéricas de procedencia egipcia satisfacían mejor las exigencias de la razón que la religión oficial grecorromana. Tanto en Grecia como en Roma la filosofía y el progreso del pensamiento se debía a la población civil, a los laicos. Los ritos religiosos eran cada vez más la expresión de un mundo que había dejado de comprenderse. Prueba de ello es que Plutarco en sus Cuestiones Griegas (Mor. 291D305A) y en sus Cuestiones Romanas (Mor. 263D-291D) intenta dar una explicación racional a muchos de esos ritos que al ciudadano co-

51 Die orientalischen Religionen im römischen Heidentum, Stuttgart $1969^{3}$, pp. 25 ss.

52 Ibid., p. 26. 
mún le eran ya completamente ajenos. En cambio, en las religiones orientales los sacerdotes tenían una formación privilegiada que les daba un indudable prestigio ${ }^{53}$. Plutarco ${ }^{54}$ afirma que los griegos más sabios fueron a Egipto y se relacionaron con sus sacerdotes y de ellos aprendieron filosofía, matemáticas, astronomía y medicina. Por último, las religiones mistéricas apelan a la conciencia individual de las personas y por la creencia en la renovación interior mediante ritos catárticos que purifican el alma y el cuerpo en la esperanza de una vida mejor descargan del fondo del inconsciente energías mucho mayores que cualquier tipo de consideración racional.

Debe añadirse a esto el hecho de que el culto a Isis y sus misterios era conocido y en cierto modo admirado desde época de Heródoto o probablemente antes; que la solemnidad y el boato de los rituales y fiestas egipcias debió de ejercer una especial fascinación en el ánimo de los habitantes de Grecia y además esta diosa egipcia por su versatilidad podía asimilarse perfectamente a las diosas del panteón griego como así ocurrió. Asimismo en época helenística y romana la brillantez y grandiosidad de la ciudad de Alejandría, centro mundial de la cultura y de los espectáculos, debió de atraer también la atención de griegos y romanos, que siempre miraron con fascinación la cultura del Nilo.

Y además, la diosa Isis introduce un elemento de feminidad, que siempre había gozado de profundo arraigo en la cultura mediterránea. Baste con recordar el culto a la Gran Madre en los pueblos mediterráneos. La religión oficial de Grecia y Roma, en cambio, era una religión de origen indoerupeo, en la que primaba el elemento masculino. Isis se presenta, en efecto, como esposa y como madre, como protectora del matrimonio y del amor conyugal, como diosa que ayuda en los partos, se cuida de los enfermos, enseña el cultivo de los frutos y que instaura la justicia no sólo en el hogar sino en el universo entero. La imagen de Isis lactans es la que más ha popularizado la iconografía. Este elemento femenino de la religión isíaca contribuyó, sin duda, a

53 F. Dunand en Le culte d'Isis... III, pp. 184 y 194 defiende que el prestigio de los sacerdotes egipcios procedía más de su distanciamiento del pueblo llano y de las costumbres rituales que le rodeaban que de la excelencia de su formación.

\$4 Sobre Isis y Osiris 10 (= Mor. 354 E.). 
su rápida difusión por toda la cuenca mediterránea pues pertenecía a su religiosidad ancestral y fue subsumido tanto por el cristianismo oriental con el culto a la Theotokos como por el del Mediterráneo occidental. Las invocaciones de Isis que aparecen en sus himnos ${ }^{55}$ y las de las letanías que se rezan a María, son muy semejantes. En los pueblos centroeuropeos, menos influidos por la cultura mediterránea, la figura de María, o el elemento femenino, siempre ha ocupado en su religiosidad un papel secundario somo se puso de relieve con la Reforma Protestante.

6. Difusión del culto en Roma: La numismática testimonia que Isis y Sarapis eran venerados en Catania (Sicilia) en el s. III a. C. ya que sus efigies aparecen en monedas de bronce que, según el profesor Manganaro $^{56}$, datan aproximadamente del año 212 a. C. Este profesor rechaza la teoría de que el culto a Isis y Sarapis se introdujera en Sicilia en época de Agatocles por influjo de su tercera esposa, Teoxena, hija de Ptolomeo II. Afirma Manganaro que el culto a los dioses egipcios debió de introducirse tras la caída de Jerónimo (214 a. C.) cuando los siracusanos renovaron y consolidaron su relación con Egipto, y piensa que la introducción del culto no se debió tanto a una política impositiva de los Ptolomeos cuanto a la atmósfera favorable que encontró en Sicilia en ese momento de la historia. La situación geográfica de Sicilia le confería una importancia significativa como ruta comercial y contribuyó a que muchos itálicos entraran en contacto con los cultos egipcios sin que esto fuera óbice para que algunos comerciantes, sobre todo en época republicana, conocieran las divinidades egipcias en otros lugares como Eretria, Calcis, Atenas o Macedonia $^{57}$. Otro centro muy frecuentado por negotiatores italianos fue Delos. Así lo atestiguan las inscripciones publicadas por Roussel y fechadas entre los años 166 y 168 a. C. en las que aparecen ciento quince nombres de personajes itálicos devotos de Isis.

55 Cf. Aretalogía isíaca de Cime, trad. esp. de L. Gil en J. Leipoldt y W. Grundmann, El Mundo del Nuevo Testamento, 3 vol., Madrid 1975, II. pp. 104-105. Y Grandjean, o. $c$., en nota 3 , pp. 8 ss., ofrece un catálogo de las aretalogías isíacas.

56 Citado por L. Vidman en Isis, p. 30.

${ }^{57} C f$. S. K. Heyob, o. c., en nota 10, p. 11. 
El testimonio epigráfico más antiguo ${ }^{58}$ del culto de los dioses egipcios en la Italia peninsular procede del año 105 a. C. Se trata de la célebre lex parieti faciendo de Pozzuoli en donde se menciona el Serapeo de la localidad, lo que nos hace suponer que si en el 105 existía el templo, el culto de Sarapis debía de estar arraigado desde mucho antes en ese lugar. Señala K. Heyob ${ }^{59}$ que Pozzuoli se convirtió en el s. II a. C. en el principal puerto comercial del sur de Italia a expensas incluso del de Nápoles y que siempre estuvo abierto a la recepción de los cultos egipcios, por lo que se difundieron rápidamente por la Campania, especialmente en los núcleos urbanos de Nápoles, Pompeya y Herculano. En Pompeya se construyó un Iseo antes del año 80 a. C. Los frescos que aún hoy podemos contemplar de algunas casas de Pompeya y Herculano son un buen testimonio del arraigo de este culto en aquellas ciudades ${ }^{60}$.

En el Mediterráneo occidental el primer testimonio del culto de Sarapis es del año 79 a. C. y procede de Castra Caecilia (actual Cáceres) en donde se ha encontrado un altar con el busto de Sarapis en sus laterales. Más reciente, pero también de época republicana es el templo de Sarapis en Ampurias ${ }^{61}$. Las relaciones comerciales de Hispania con Alejandría están atestiguadas por Estrabón (II 3,4). Una cabeza de Sarapis que actualmente se encuentra en el Museo Episcopal de Vic pero que procede de Valladolid, es datada por I. Rodà ${ }^{62}$ a finales del s. II o comienzos del III de nuestra era, y según la profesora Rodà esta representación serápica vallisoletana «és podria posar en

ss Cf. L. Vidman, SIRIS, n. 497 y V. Tran Tam Tinh, Le culte des divinités orientales en Campanie, Leiden 1972, p. 58.

s9 O. c., pp. 12-13.

60 Sobre el culto de Isis y Sarapis en Campania, véase el libro de V. Tran Tam Tinh citado en la nota 58.

61 Cf. A. García y Bellido, El culto a Sarapis en la Península Iberica, Madrid 1956, p. 35; id. Les religions orientals dans l'Espane romaine, Leiden 1967, pp. 125-130 y C. G. Wagner-J. Alvar, «El culto de Sarapis en Hispania» en La Religion Romana en Hispania, Madrid 1981, pp. 323-333. Véase también la inscripción ampuritana en que, si la reconstrucción es correcta, se menciona a un alejandrino que debió de hacer alguna ofrenda a Sarapis en L. Vidman, SIRIS, n.768 y M. Almagro, Las inscripciones ampuritanas Barcelona 1952, pp. 89-90.

62 Catàleg de l'Epigrafia i de l'Escultura Clàssiques del Museu Episcopal de Vic, Vic 1989 , p. 58. 
relació segurament amb el focus de culte que sembla irradiar de l'establiment de comerciants a Legio (Lleó) pel nor'oest de la peninsula ibèrica».

En Roma el culto de las divinidades egipcias se popularizó y encontró muchos adeptos en la época de Sila especialmente en las clases más bajas de la población. A. Alföldi ${ }^{63}$, que ha realizado un serio estudio con base en la numismática sobre el culto de Isis y los movimientos sociales en los últimos años de la República, sostiene que en la colina capitolina había una asociación de adoradores de Sarapis, unidos en parte por su insatisfacción con el poder dominante, que expresaban su descontento en la acuñación de monedas. A este hecho piensa el profesor Alföldi que se debe toda la simbología isíaca que aparece en las monedas romanas en época de Sila y en los años sucesivos. Es mérito también de Alföldi haber descubierto un denario con la primera imagen de Isis Panthea, acuñada, según este profesor, en el edilato de M. Plaetorius Cestianus, un asociado de Crasso.

Según Alföldi, Crasso se valió del edil con autorización para acuñar monedas para alentar la revolución. Vidman ${ }^{64}$ piensa, por el contrario, que el edil curul hizo estas acuñaciones con el fin de dar gusto a la parte de la población más insatisfecha, entre la que se contaban muchos adeptos de los dioses egipcios, aunque no se cierra a la posibilidad de que el edil Plaetorius Cestianus fuera una especie de quintacolumnista pues, al parecer, estaba familiarizado con el culto egipcio ya que podría ser hijo de M. Plaetorius Flaccus, liberto de Delos. Excepción hecha de la época de Sila, los cultos alejandrinos fueron siempre prohibidos oficialmente en Roma durante la época republicana. En los años 59, 58, 53, 50 y 48 a. C. los altares isíacos fueron destruidos aunque de nuevo levantados por la piedad popular. En el segundo triunvirato, la actitud de los triúnviros Octaviano, Marco Antonio y Lépido fue menos hostil a los cultos egipcios. En el año 43 a. C. se decretó la construcción de un templo de Isis y Sarapis en Roma. Probablemente la situación política así lo exigía. No obstante, no hay

63 «Isiskult und Umsturtzbewegung in letzten Jahrhundert der römischen Republik», Schweizer Münzblätter V, 1954, pp. 25-31.

${ }^{64}$ Isis, pp. 101-105. 
pruebas de que la construcción de este templo se llevara a término. Y Augusto, cuando se hizo con el poder absoluto, volvió a mostrar aquella aversión a los cultos extranjeros que había imperado en época republicana. Los templos isíacos quedaron relegados a los arrabales de la ciudad, con lo que también se intentaba favorecer una política de vuelta a la religiosidad tradicional $(28 \mathrm{a}$. C.). Las revueltas que surgieron en Roma en el año 21 a. C. cuando Octaviano se fue a Sicilia es muy probable que estuvieran promovidas por los Isiaci. De ahí la resolución de Agripa de prohibir las prácticas religiosas de los egipcios en un radio de una milla del pomerium (Casio Dión LIX 6,6).También Tiberio, en el año 19 de nuestra era, so pretexto de que una dama, Paulina, había sido seducida por un caballero, Decio Mundo, en el templo de Isis con la colaboración de los sacerdotes de la diosa, ordenó que los sacerdotes fueran crucificados, desterró a unas cuatro mil personas a Cerdeña y obligó a otras a salir de Italia a menos que cambiaran su credo religioso.

Desde Italia ya en los primeros años del imperio el culto de Isis se difundió por todo el Occidente ${ }^{65}$ a excepción de Hispania y Norte de Africa en donde el culto estaba instaurado desde hacía tiempo por la relación directa de las gentes de estas provincias con Alejandría. Con Calígula cambiaron las perspectivas para los seguidores de Isis y Sarapis. Este emperador sintió una gran admiración por el boato de la corte egipcia y la divinización de sus monarcas. Construyó un Iseo y un Serapeo en el Campo de Marte, integró los festivales isíacos dentro de los sacra publica populi Romani y en su palacio del Palatino decoró una habitación -la célebre Aula Isiaca- con motivos de la religión egipcia. No tenemos testimonios epigráficos de esta época y muy pocos de los años de gobierno de Claudio y Nerón ${ }^{66}$, si bien sabemos que estos dos emperadores mantuvieron también una actitud de tolerancia respecto a la religiosidad egipcia. Volvió a promoverse el interés por los cultos egipcios en época de los Flavios, en gran medida porque acariciaban la idea de convertirse en monarcas divinizados en vida al estilo de los egipcios. De Vespasiano sabemos que antes de su 
ascensión al trono estuvo en el Serapeo de Alejandría ${ }^{67}$ y que celebró con su hijo Tito el triunfo de éste sobre los judíos pernoctando en el Iseo del Campense ${ }^{68}$, de donde partió la procesión triunfal. Domiciano en el año 92 reconstruyó el templo de Isis del Campo de Marte, que había sido quemado en el 80 , y reconstruyó y amplió el de Benevento en el 88. Allí ha aparecido una estatua de Domiciano con atuendo faraónico, inscripciones con caracteres jeroglíficos y aclamaciones al emperador al estilo egipcio. En el siglo II, Hadriano, si al principio de su imperio fue reacio a favorecer los cultos extranjeros, a partir de su viaje a Egipto y de la muerte de Antínoo en el Nilo se sintió atraído por el mundo y la religiosidad egipcia. Reconstruyó el Serapeo de Alejandría y hacia el año 130-131 se acuñaron monedas con las figuras de Isis y Sarapis y de nuevo en los años 134 a 138 con la efigie de Isis. En su propia villa de Tívoli, Hadriano imitó el exterior del Serapeo de Canope. En época de Hadriano se le concedió a Sarapis el reconoci-

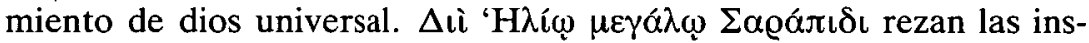
cripciones de la época ${ }^{69}$. Es en este momento cuando el culto de las divinidades egipcias alcanza su expansión definitiva por el Occidente romanizado. La arqueología y la epigrafía documentan su existencia en Panonia ${ }^{70}$, Dalmacia ${ }^{71}$, la Dacia ${ }^{72}$, Moesia ${ }^{73}$, Germania ${ }^{74}$, las Galias $^{75}$, Britania ${ }^{76}$ y en el Norte de Africa en Cartago ${ }^{77}$, Numidia ${ }^{78}$, Mauritania $^{79}$, Tripolitania ${ }^{80}$ y Cirenaica ${ }^{81}$. En época de Marco Aurelio y Antonino Pío también se acuñaron monedas con la imagen de Isis.

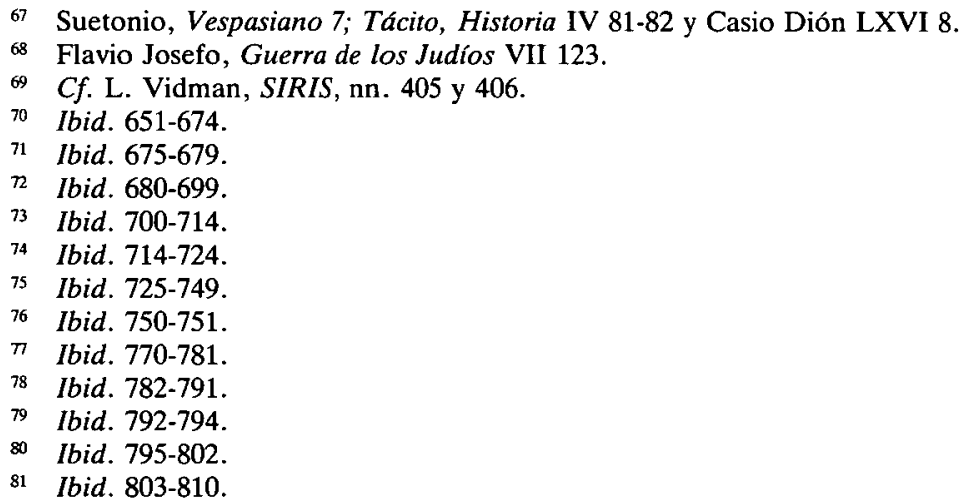


Cómmodo llegó a participar activamente en los rituales de la religiosidad alejandrina, con lo que se granjeó un gran prestigio incluso entre las clases más elevadas. Septimio Severo viajó a Egipto para conocer in situ la religión de Sarapis. Pero fue en el gobierno de Caracalla cuando el culto de las divinidades egipcias alcanzó su mayor popularidad. Caracalla fue llamado philosarapis e hizo que se le representara en las monedas a imagen de Sarapis, como un cosmócrator, con cielo y tierra bajo su poder. Caracalla legalizó el culto de Isis y Sarapis en el año 217 y levantó la prohibición de construir templos consagrados a las divinidades egipcias dentro del pomerium. Según Minucio Félix (Oct. 23,1$)$ a partir de Caracalla no volvió Isis a ser considerada en Roma como una diosa extranjera. Caracalla construyó en el Quirinal y en el Monte Celio espléndidos templos a los dioses alejandrinos. Después de Caracalla disminuyó el interés de los emperadores por las divinidades egipcias, si bien siguió su culto junto con el de las divinidades tradicionales romanas. Las monedas son un excelente reflejo del sicretismo entre dioses romanos y dioses extranjeros. En tiempo de Diocleciano se acuñaron monedas que por un lado llevaban la efigie de Neptuno y por otro la de Isis. El culto de las divinidades egipcias persistió hasta fines del s. IV. Así lo testifica la numismática. A. Alföldi ${ }^{82}$ ha demostrado que entre los años 379 y 395 en época de Juliano se hizo en Roma una emisión de moneda en la que aparecían los bustos de Sarapis e Isis. En el año 394 se celebraron en Roma las últimas fiestas oficiales en honor de Isis pero el emperador Teodosio se propuso arrasar todos los cultos paganos en favor del Cristianismo. Bajo su gobierno se llevó a cabo una clausura masiva de templos en Alejandría (386-388) y en el año 391 se destruyó por orden suya el Serapeo de dicha ciudad. Estas acciones supusieron un golpe definitivo a la religión de Isis y Sarapis. No obstante, el culto de Isis continuó en la clandestinidad hasta finales del s. V en ciertas localidades de Egipto. Así por ejemplo en Menuti ${ }^{83}$, donde se descubrió por una denuncia en tiempos de Pedro el Monje (482-490), quien organizó

82 A Festival of Isis in Rom under the Christian Emperors of the IVth. Century, Budapest 1937, p. 36.

83 Cf. N. Fernández Marcos, o. c., en nota 18, p. 17. 
una nueva expedición con la ayuda de las autoridades civiles para arrasarlo y terminar definitivamente con él.

6. Suplantación de culto: El numen de la divinidad se aferra al lugar y en él permanece ${ }^{84}$. La gente continúa acudiendo, aun cuando cambie la divinidad tutelar y la religión. Por ello Menuti se convirtió de nuevo en centro de peregrinación. El obispo Cirilo, inquieto por la atracción que aún ejercía sobre la población el lugar en donde Isis había sido venerada y visitada por muchos enfermos, decide trasladar los restos de dos hombres que reconoce como San Ciro y San Juan desde la iglesia de San Marcos de Alejandría a Menuti. Fundamenta su decisión del traslado en una revelación divina para darle así mayor autoridad. No fue sin intención el que el patriarca Cirilo eligiera el nombre de Ciro (Kũoos) para suplantar el culto de Isis en Menuti donde se la llamaba Kv@á («Señora»). El mismo escribe cuando quie-

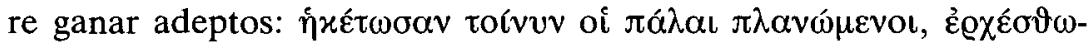

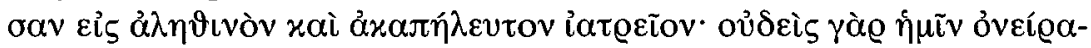

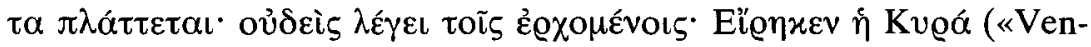
gan, pues, los que en otro tiempo andaban en el error; acérquense al hospital verdadero e insobornable; puesto que ya nadie finge sueños; nadie dice a los que se acercan: Lo ha dicho la Señora») ${ }^{85}$. El éxito de la suplantación de culto fue total. En el s. VI el templo de Ciro y Juan fue tan visitado como lo fuera en su tiempo el de Isis de esa localidad. «En el pueblo (scil. Menuti) -afirma N. Fernández Marcos ${ }^{86}$ - se renovaron las antiguas prácticas y los procedimientos curativos al uso en tiempo de Isis. Se recurrió como en el pasado a los sueños y a las curaciones por el método de la incubatio».

7. Actividades terapéuticas en los santuarios: Incubatio: Quisiera poder demostrar que en los templos egipcios, griegos y romanos de Isis y Sarapis se practicó entre otras la actividad terapéutica mediante

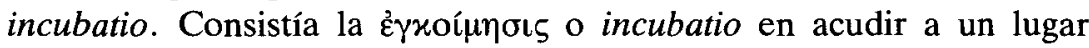

R. Herzog, Der Kampf um den Kult von Menouthis, Münster 1939, pp. 119 ss. PG LXXVII 1103.

O. c. p. 19. 
sagrado con el fin de entablar contacto mediante el sueño con alguna divinidad. Responde este fenómeno a dos rasgos muy definitorios de la personalidad humana. Uno es la insatisfacción permanente con la realidad dada y otro la esperanza también permanente de superar los límites de esa realidad. Responde también a la creencia de que en el recinto es más fácil el contacto con el dios, héroe o santo. Los antecedentes ctónicos de la incubatio explican, en parte, esa creencia. En parte se explican también por la convicción de que sólo en el estado somnial podía el hombre acceder a la divinidad. Incluso un profesional de la medicina como era Hipócrates afirma que hay sueños de origen divino que anuncian, sea a las ciudades o a los particulares, bienes o males (De victu IV 87). En el cristianismo, el ilustrado obispo Sinesio de Cirene ${ }^{87}$ afirma que sólo en el sueño la divinidad viene a reunirse con el alma, pues sólo entonces se halla ésta liberada de la ataduras espacio-temporales. Y además, según Sinesio, el sueño tiene la ventaja de ser algo común a todos los hombres y de que nigún tirano puede prohibirlo, a no ser que prohiba a sus súbditos dormir. Responde también la incubatio a un concepto filantrópico de la humanidad. Se ha especializado, pues, el término de incubatio para designar ese fenómeno que entra en el ámbito de la medicina sacra y popular, por el que personas con problemas de salud acudían a un lugar sagrado con el fin de pernoctar allí para recibir la curación o indicaciones terapéuticas del dios mediante una visión onírica. Y en ciertos casos, según cuentan las crónicas, los enfermos se marchaban liberados de sus dolencias. Se ha estudiado este fenómeno tanto en los templos de Asclepio ${ }^{88}$ como en los templos cristianos del Mediterráneo oriental ${ }^{89}$, en donde la

$87 \quad P G$ LXVI 1309.

88 L. Deubner, De Incubatione, Berlín 1900; O. Deubner, Das Ask lepieion von Pergamon, Berlín 1938; L. Edelstein, Asklepios, Baltimore, 1945; R. Herzog, «Die Wunderheilungen von Epidauros», Philologus, Suppl. XXII 3, 1931; P. Kavvadias, Tò

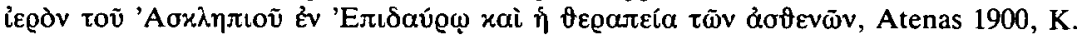
Kerenyi, Asklepios. Archetypal Imagen of the Physician's Existence, Londres 1960 y L. Gil, Therapeia. La medicina popular en el mundo clasico, Madrid 1969, pp. 349-399.

89 M. Hamilton, Incubation or the Cure of Diseases in Pagan Temples and Christian Churches, Londres 1906; N. Fernández Marcos, o. c. en nota 18 y M. López Salvá, Estudio de la incubatio cristiana en la primitiva iglesia oriental (excepto en Menuti) a través de las colecciones griegas de milagros, Madrid 1975 (tesis doctoral inédita); id. «El sueño incubatorio en el cristianismo oriental», Cuadernos de Filología Clásica X 1976, pp. 147-188. 
piedad de los fieles les llevó a redactar unas veces para edificar y otras para entretener, colecciones de tháumata en las que se relatan los favores salutíferos obtenidos en el curso de los ensueños.

No se puede entender la actividad salutífera de los templos en donde se practicaba la incubatio, si antes no se ha captado la importancia que desde antiguo se ha conferido a los ensueños. En todas las creencias de las culturas antiguas se han admitido las epifanías de los dioses en los ensueños o el envío de éstos por la divinidad. En Egipto la creencia en las revelaciones oníricas contaba con una larga tradición como contaba, asimismo, con una larga tradición la actividad curadora de Isis. El papiro Ebers del s. XVIII a. C. (1700 a. C.) relata que Isis preparó unos polvos para aliviar el dolor de cabeza del dios Rā. Una de las facetas más atractivas de Isis es la de diosa curadora. Así lo confirma Diodoro ${ }^{90}$ cuando relata que los egipcios aseguran que «Isis ha sido descubridora de muchos fármacos para la salud y que tenía gran experiencia en la ciencia médica, que se presentaba en los sueños y daba a los enfermos remedios para sus enfermedades y que los que la obedecían sanaban inmediatamente». Celso ${ }^{91}$ en su ataque a los cristianos escribió que si Cristo tenía ciertos poderes fue porque en una estancia en Egipto los aprendió de las divinidades egipcias.También J. Lydus afirma que se dice en Egipto que «Isis es dadora de

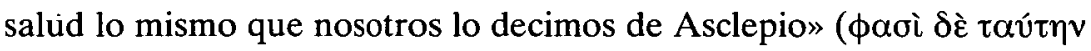

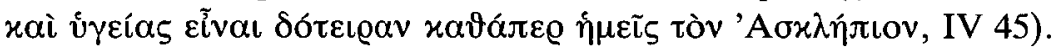

Habida cuenta de la tradición de las revelaciones oníricas en Egipto y de los antecedentes de Isis como diosa salutífera, no es de extrañar que en sus templos, especialmente a partir de época helenística, se practicara la incubatio. Piénsese que en esa época tanto en la Grecia continental (Epidauro, Atenas) como en Asia Menor (Pérgamo, Efeso) como en las islas (Cos) esta práctica religiosa estaba en pleno vigor. En el ámbito literario el miniambo IV de Herodas es un reflejo

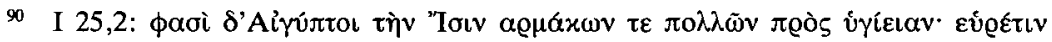

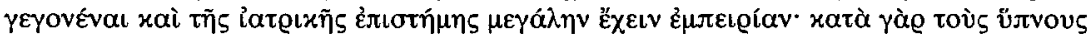

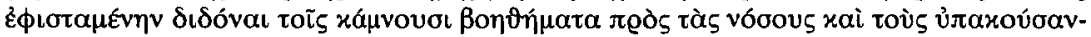

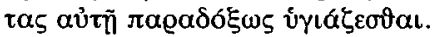

91 Cf. Orígenes, Contra Celso I 28. 
de la popularidad del Asklepieion de Cos en época helenística. Veamos ahora qué datos se nos ofrecen en lo tocante a esta práctica en los templos de Isis y Sarapis. Estrabón (XVII 1,17) nos habla de que en su época ilustres hombres iban a dormir a los templos de Canope y Menuti, y que algunos escribían las curaciones allí realizadas lo mismo que se hacía en los Asklepieia de Epidauro, Cos y Trikka (VIII 6,15). Tenemos noticia también por una inscripción publicada en 1860 por Egger de que un tal Aristilo no pudo obtener la curación de Sarapis a pesar de haber recibido sueños en su templo de Menfis. También en un papiro publicado por U. Wilcken ${ }^{92}$, un personaje de nombre Haryotes nos informa que estuvo en el templo de Isis de Kerkeosiris a causa de una enfermedad que le afectaba. Al Serapeo de Esmirna acude Elio Aristides, el hipocondríaco más célebre de la literatura griega, a buscar remedio a sus múltiples males. Allí se le aparecen los tres dioses, Asclepio, Isis y Sarapis. Recordemos que la estancia de Aristides en Pérgamo, en cuyo Asklepieion pasó tres años como incubante (144-146) le familiarizó con Asclepio y el viaje que había hecho en el 141 a Egipto le había familiarizado con Isis y Sarapis. Así explica Aristides una de sus experiencias oníricas en el Serapeo de Esmirna: "Apareció también una luz de parte de Isis y otras cosas inenarrables que llevan a la salvación y se apareció también Sarapis aquella misma noche y a la vez también el mismo Asclepio, admirables por su belleza

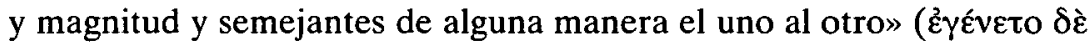

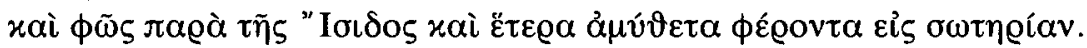

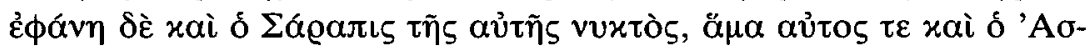

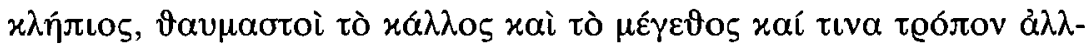

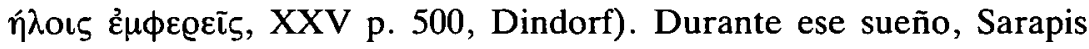
con una lanceta le hizo a Aristides una incisión en la cara para quitarle las impurezas y reintegrarle a su estado normal. El halo de luz que rodea a la persona divina así como su tamaño y belleza son rasgos tópicos de los relatos de las epifanías oníricas ${ }^{93}$. Aristides, visitante habitual de los santuarios, dice, en efecto, que «cada uno de sus días 
y de sus noches ofrece materia para escribir si alguno de los presentes hubiera querido describir lo sucedido o narrar la providencia del dios, las indicaciones que hacía, unas veces a las claras porque se presenta-

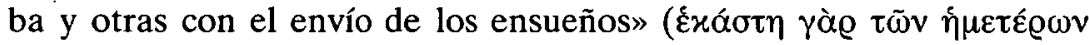

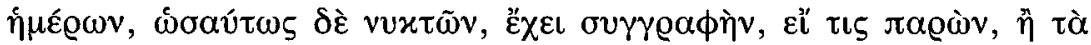

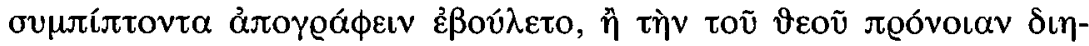

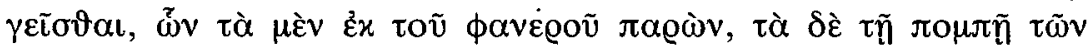

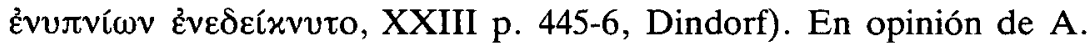
Bouché- Leclercq ${ }^{94}$, Aristides estaba absolutamente convencido de que su salud era objeto de las preocupaciones divinas y por eso pasó tanto tiempo en los templos.

Artemidoro $^{95}$ hace referencia a Gémino de Tiro, Demetrio de Falero y Artemón de Mileto, quienes en tres, cinco y veintidós libros respectivamente recogieron muchas visiones oníricas y, sobre todo, «las prescripciones y las curaciones otorgadas por Sarapis».

Todos estos datos apuntan a que los enfermos acudían a los templos de Isis y Sarapis y que allí pernoctaban, y con toda probabilidad muchos verían -como Aristides- en sueños al dios o a los dioses que les curaban o les indicaban los medios de recuperar' la salud.

Los documentos de época ptolomaica publicados por U. Wilcken ${ }^{96}$ atestiguan la existencia de Évvлvıox@í $\alpha \iota$ «intérpretes de ensueños» tanto en el Serapeo de Menfis como en el de Alejandría y atestiguan también que a esos templos acudían enfermos en busca de curación. Wilcken obra con mucha cautela a la hora de juzgar el carácter de los ensueños que se recibían en el Serapeo y pone en tela de juicio que allí se practicara la incubatio pues -dice- los ensueños que se relatan «son completamente habituales como cualquier persona en cualquier momento puede tener" ${ }^{97}$. Ante esta afirmación de Wilcken cabe se-

94 Histoire de la Divination dans l'Antiquité, 4 vols., Nueva York 1975 (= París 1879-1882), I, p. 307.

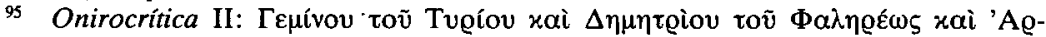

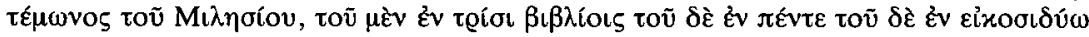

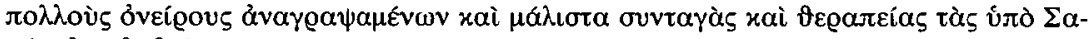

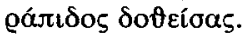

96 Urkunden... I, pp. 48-49 y 77-79.

97 Ibid., p. 350. 
ñalar que los ensueños que los enfermos reciben en los templos de incubatio, también son «ensueños completamente habituales» y normales, que «cualquier persona puede tener», pues en ellos emergen las preocupaciones y los deseos más profundos de los enfermos, como sucede en cualquier tipo de ensueño. Así, cuando una persona afirma haber visto en el Serapeo de Menfis a la diosa Tages con una agradabilísima voz y una bella figura, y a Taus sonriente y con un pie muy puro $^{98}$, en ese ensueño podemos percibir los mismos topoi, propios de la literatura aretalógica que se encuentran en las colecciones cristianas de milagros escritas para edificación y deleite de los enfermos de los templos de incubatio. Por ejemplo, lo mismo que en el templo de Cosme y Damián ${ }^{99}$ se les aparecen los santos a los enfermos con el atuendo de médicos indicándoles el remedio que alivie sus preocupaciones, en el Serapeo de Menfis una persona que acudió al templo vio en sueños al dios Ammón, tirando de un toro, evidentemente Apis, y haciendo una imposición de manos ${ }^{100}$. También una inscripción datada en el s. III-II a. C. hallada en Menfis hace refencia a un cretense que por orden del dios interpretaba los ensueños ${ }^{101}$. El que entre el personal fijo al servicio del templo de Menfis se encuentren los intérpretes

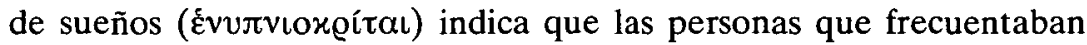
ese templo, prestaban una especial atención a los fenómenos oníricos, por considerarlos, sin duda, enviados por la divinidad.

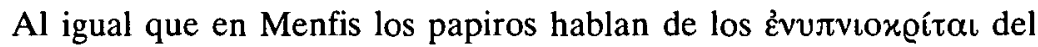
Serapeo, en Delos las inscripciones antiguas atestiguan la existencia de ỏveloox gital en su Serapeo ${ }^{102}$. Conviene recordar que fue un sacerdote de Menfis el que introdujo el culto de Sarapis en la isla de Delos y que en cumplimiento de una orden de Sarapis a su sacerdote cuando dormía

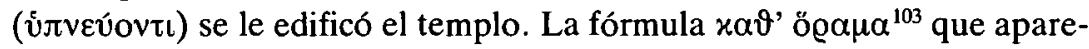
ce en las inscripciones de Delos, expresa también la creencia en las

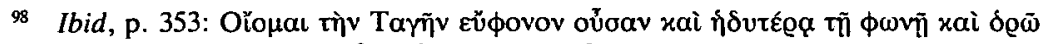

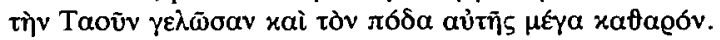

99 Cf. M. López Salvá, «El sueño incubatorio:...» pp. 164-168.

100 Cf. W. Wilcken, Urkunden..., p. 353.

101 Cf. E. Bernard, Inscriptions métriques de l'Egypte greco-romaine, París 1969, p. 436.

102 Cf. P. Roussel, o. c. en nota 38 inscr. n. 64, 84, 119, 120, 123, 169, 175 y 201.

103 Ibid. n. 62, 123, 201 y 210. 
revelaciones del dios durante el sueño a los que frecuentaban el Serapeo. Isis aparece en Delos asimilada a la diosa Hygieia, lo que también pone de manifiesto sus virtualidades terapéuticas.

En el Iseo de Atenas se ha hallado una inscripción ${ }^{104}$ de la época de Hadriano, en la que se menciona la donación de una mujer, que ejercía en el templo de ỏveıox@ítıs y además de $\lambda v \chi v a ́ \pi \tau \varrho ı \alpha$. Las procesiones de antorchas como la interpretación de los ensueños seguían siendo funciones importantes en la vida ritual y cultural de los templos de Isis en época imperial. En otra inscripción votiva a Isis de fines del s. II o principios del I a. C. de Atenas ${ }^{105}$ se dice que fue ofrecida en el tiempo que el antioqueno Dionisio interpretaba los sue-

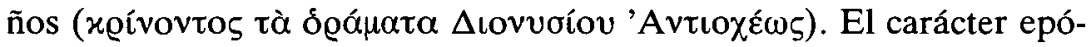
nimo del intérprete de sueños es señal de la alta consideración en que se debían de tener sus funciones y en consecuencia de la importancia de la vida onírica en el mundo cultual de estas divinidades.

En el Peloponeso, en Epidauro, hay dos altares a Isis y Sarapis, que fueron financiados, según Pausanias (II 27,5), por un miembro de la boulé de Epidaruo, Antonino, en honor de los dioses curadores bajo su advocación egipcia. «La asociación de los dioses egipcios a las grandes divinidades curadoras del mundo griego, afirma F. Dunand ${ }^{106}$, no tiene nada de sorprendente, pues la función curadora les era reconocida en Grecia lo mismo que en Egipto». En el Peloponeso, donde merecen recordarse los santuarios egipcios de Corinto y Cenchres, celebrado por Apuleyo, los dioses egipcios tuvieron, en palabras de $\mathrm{Du}$ nand ${ }^{107}$, «un carácter esencialmente curador, lo que explica su asociación con Asclepio".

Las fórmulas $x \alpha \tau$ à őva@ "durante el ensueño» ${ }^{108}$, que aparece en

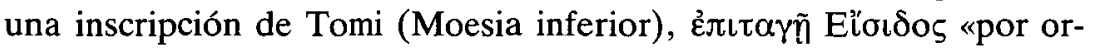

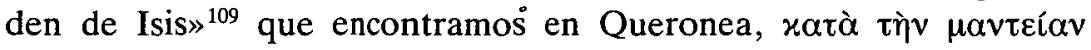

$104 C f$. L. Vidman, SIRIS, n. 16.

$105 C f$. IG $\mathrm{II}^{2}$; S. Dow, o. c. en nota 49 , p. 208 y L. Vidman, SIRIS, n. 5, quien afirma que el óvel@ox@ítns es somniorum a diis missorum interpres.

106 Le culte d'Isis..., II p. 162.

107 Ibidem.

108 Vidman, SIRIS, n. 706.

109 Ibid. 69. 


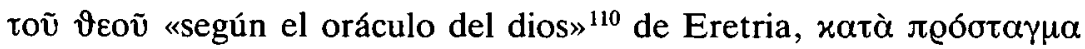
"por orden»" 111 , registraba en Tenos, Cos, Efeso y Chipre, o la de

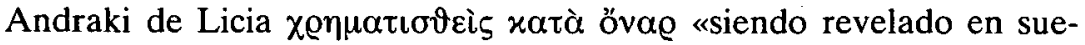
ños» ${ }^{112}$ responden al estilo formulario que emplean los aretólogos o los enfermos que reseñaban sus experiencias oníricas en los Asklepieia

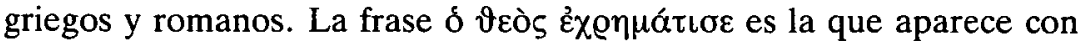
más frecuencia en las inscripciones del Asklepieion de la isla del Tíber $^{113}$. Para Macrobio ${ }^{114}$ en su clasificación de los ensueños el $\chi \varrho \eta \mu \alpha-$

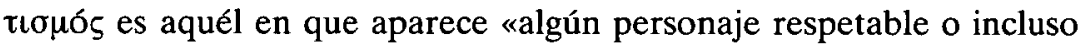
un dios y revela sin simbolismo lo que sucederá o no sucederá, lo que debe o no debe hacerse».

No podemos olvidar en este recorrido una inscripción del s. III o IV de nuestra era grabada en un muro de un templo de Abidos, ciu-

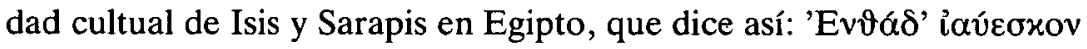

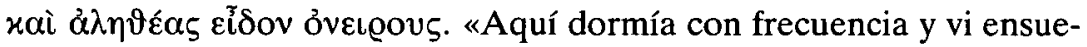
ños verdaderos» ${ }^{115}$. Aunque en la época tardía en que esta inscripción está fechada, ya no se daba culto en este templo a Sarapis sino a Bes, divinidad local, nos revela, sin embargo, que efectivamente existía la costumbre de dormir en el templo. También en el templo de Hatshepsout en la ciudad egipcia de Deir-el-Bahari, según puede deducirse del testimonio de las inscripciones ${ }^{116}$, había la costumbre de ir a pernoctar al templo con el fin de recibir la salud del favor de la divinidad. En Pompeya, según Tran Tam Tinh ${ }^{117}$, los fieles más devotos debieron de practicar el ritos de la incubatio, quedándose a dormir en unas camas del pastophorion dispuestas para tal efecto.

El hecho de que en los Asklepieia, como por ejemplo en el de Atenas, se encuentren inscripciones dedicadas a las divinidades egip-

110

111

112

113

114

115

116 XXIII ss.

11 Le culte d'Isis a Pompéi, Paris 1964, p. 111.

Ibid. 75.

Ibid. 152, 247, 296 y 354.

Ibid. 348.

Cf. E. Bernard, o. c. en nota 101, p. 525.

Cf.. M. Bernier, L'île tibérine dans l'antiquité, París 1902.

Som. Scip. I 3,8; Artemidoro de Efeso, Onirocrítica I 1.

Cf. A. Bataille, Inscriptions grecques du temple de Hatshepsout, París 1951, pp. 
cias (IG II 4772 y 4815) y que en los Serapeia, como en el de Delos, haya dedicaciones a Asclepio e Hygieia ${ }^{118}$ indica el prestigio de los dioses egipcios como dioses curadores. También en las provincias romanas se encuentran inscripciones conjuntas a Aesculapio, Saluti, Serapi, Isidi como la hallada en la Legio VII Gemina de Hispania ${ }^{119}$ o la de Olbia en Moesia ${ }^{120}$, que nos informa que en época de Alejandro Severo un particular preparó con dinero de su bolsillo un templo con pórtico, techados, puertas y ventanas «a los dioses que estaban pron-

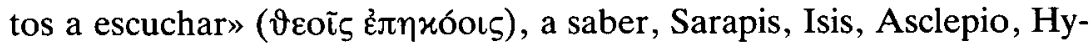
gieia y Poseidón. También en el Lacio ${ }^{121}$ e incluso en Roma ${ }^{122}$ se invoca a Isis para recobrar la salud, lo que indica cómo las habilidades terapéuticas que se atribuían a Isis debieron de ser un factor importante en la difusión de su culto. Sin duda, los fieles devotos irían a los numerosos templos que se le dedicaron en todo el imperio y permanecerían allí durante un tiempo en espera de la curación.

De hecho, lo que ocurriría en el acto incubatorio, como ha señalado L. Gil ${ }^{123}$, es que el enfermo que acudía al lugar sagrado tenía especialmente sensibilizado su instinto de curación y lo sacralizaba en la figura del curador. Nadie duda hoy de la función compensatoria de los ensueños y de cómo emergen en ellos muchas preocupaciones de la vigilia. C. Jung ${ }^{124}$ afirma que los sueños «no se sitúan por completo al margen de la continuidad de la conciencia» sino que son en muchas ocasiones el resultado de los contenidos psíquicos que los han precedido.

Teniendo en cuenta estas precisiones, estaremos en condiciones de entender que muchas de las curaciones que se realizaron en los templos fueran a través de las apariciones oníricas de las divinidades. Es una experiencia frecuente que los fieles que acuden a los templos

118 Cf. P. Roussel, o. c. en nota 38, n. 124, 204 y 205.

119 Cf. Vidman, SIRIS, n. 769 a.

120 Ibid. Véanse también inscrip. n. 143,161 y 337, en las que se invoca conjuntamente a las divinidades griegas y a las egipcias en la isla de Melos, en Lebena (Creta) y Kalecik, localidad junto al río Halys. $C f . I G \mathrm{IV}^{2} 534$ y 535 e $I G$ V 2 y 269.

121 Cf. L. Vidman, SIRIS, n. 511 y 538.

122 lbid. 411.

123 O. c. en nota 88, p. 43.

124 Energética psíquica y esencia del sueño, Buenos Aires 1954, pp. 108 y 111. 
crean ver a las divinidades tutelares del templo durante el sueño. Podríamos hacer nuestras en lo que respecta a las curaciones por incubatio las palabras de Bouché-Leclercq ${ }^{125}$ cuando afirma que «se tiene ante los ojos en pleno ejercicio, la sorprendente facultad de creer que genera por sí misma las pruebas de que se nutre su convicción».

Deben, además, enmarcarse estas prácticas en unos templos donde la actividad sacerdotal era importante, en donde los neófitos esperaban la llamada de la diosa para iniciarse en sus sagrados misterios y en donde todas las ceremonias rituales se llevaban a cabo con exquisita pulcritud. Diariamente la imagen de la diosa, al despuntar el día, era vestida y adornada con joyas y ornamentos, y por la noche se procedía a la ceremonia inversa. En algunas inscripciones atenienses de época

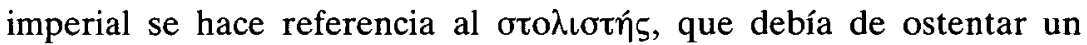
cargo de elevado rango, pues se le menciona inmediatamente después del sacerdote epónimo. También en las inscripciones latinas ${ }^{126}$ se menciona a la ornatrix fani, que cumpliría esas mismas funciones. Apuleyo (XI 9) habla de jóvenes con espejos resplandecientes, de otras que portaban peines de marfil y ungüentos olorosos. Estos datos pueden darnos una idea de cómo se preparaba a la diosa para la contemplación de sus fieles. Nos ilustran también sobre la importancia de las procesiones, la música y la danza entre los devotos isíacos, los frescos de Pompeya y Herculano ${ }^{127}$. Plutarco ${ }^{128}$ afirma que en los templos de los dioses egipcios se hacían tres ofrendas diarias de incienso. Por la mañana quemaban resina para sanear el aire con la emanación y reanimar el espíritu en el cuerpo. Al mediodía exhalaban mirra para disolver la concentración de la atmósfera circundante. Y a la puesta del sol hacían exhalaciones de kyphi. Su exhalación, dice Plutarco, arrastra suavemente hacia el sueño y disipa las preocupaciones cotidianas, y por su blanda suavidad pule la facultad imaginativa y receptiva de los sueños. Elio Aristides ${ }^{129}$, que tan bien conocía los santuarios de los

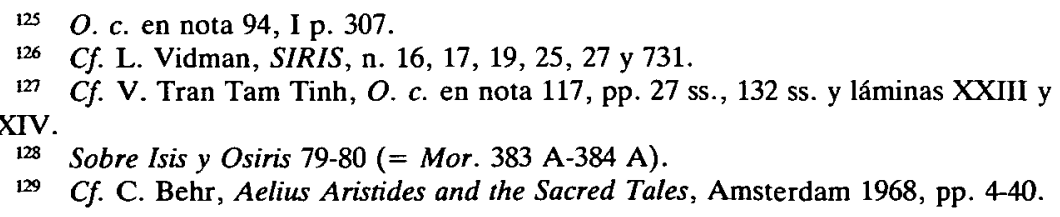


dioses egipcios, relata que en una ocasión se le prescribió en sueños kyphi con vino (roıфì $\mu \varepsilon \tau \grave{\alpha}$ oĭvov, XXIII p.452, Dindorf).

Este clima ambiental favorecería evidentemente tanto las experiencias místicas de los iniciandos como el desencadenamiento de procesos oníricos en los incubantes. Como L. Gil ${ }^{130}$ sugiere, de la conjunción del optimismo psicológico y de la vis medicatrix naturae podría surgir el milagro curativo. Ha señalado el psiquiatra jungiano C. A. Meier ${ }^{131}$ que en la práctica de la incubatio se desarrolla, al igual que en la iniciación mistérica, todo un simbolismo de muerte y renacimiento y que en la experiencia subjetiva del contacto con la divinidad emergen unas fuerzas de renovación interior que corresponden a ese despertar de Heilkräfte que están en la base de todo proceso de autocuración. Creo que esas «fuerzas salutíferas» o si se prefiere la vis medicatrix naturae explican, al menos en parte, las curaciones que acaecían en los templos de Isis, Sarapis, Asclepio o cualquier otra divinidad visitada por personas enfermas o con preocupaciones, y explican, asimismo, la popularidad que en Grecia y en Roma alcanzaron estas divinidades tan cercanas a las cuitas cotidianas de la humanidad.

Universidad Complutense

Mercedes López Salvá

130 O. c., en nota 88 , p. 393.

131 Antike Inkubation und moderne Psychoterapie, Zurich 1949, pp. 108 ss. y «Le rêve et l'incubation dans l'ancienne Grèce» en Le rêve et les sociétes humaines, París 1967, pp. 290-305. 